\title{
Chapter
}

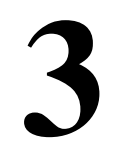

\section{Transparência e Transformação Digital: O Uso da Técnica da Linguagem Simples}

\author{
Claudia Cappelli, Vanessa Nunes e Rodrigo Oliveira
}

\begin{abstract}
This chapter presents a proposal for a short course on the use of Plain Language to support Transparency and the development of best practices for Digital Transformation. The objective of the short course is to introduce the concepts of Plain Language as a technique that can support the process of understanding the citizen and, consequently, Transparency and Digital Transformation, as a matter of public interest - right to citizenship. It aims to motivate participants to the challenges associated with (a) ensuring citizen understanding of public information, (b) providing Transparency in democratic contexts and (c) the use of emerging techniques that can help promote Transparency through Digital Transformation.
\end{abstract}

\section{Resumo}

Este capítulo apresenta o conteúdo utilizado para construção de um minicurso sobre a utilização da Linguagem Simples como suporte à Transparência e ao desenvolvimento das melhores práticas para Transformação Digital. O objetivo é apresentar uma introdução aos conceitos da Linguagem Simples (Plain Language) como uma técnica que pode apoiar o processo de entendimento do cidadão e consequentemente de Transparência e Transformação Digital, como uma questão de interesse público direito à cidadania. $O$ minicurso pretende motivar os participantes para os desafios associados: (a) a garantia do entendimento de informações; (b) ao fornecimento de Transparência em contextos democráticos; $e(c)$ ao uso de técnicas emergentes que podem auxiliar à promoção da Transparência através da Transformação Digital.

\subsection{Introdução}

As áreas da vida humana moderna estão sendo absorvidas, aproximadas ou incorporadas ao digital [Mcnutt, 2014]. O uso de sistemas de informação para oferecer produtos e serviços é um processo sem volta. Sabemos que o mundo, cada vez mais e com mais velocidade, tem se tornado amplamente digital. Os benefícios vão desde rapidez no atendimento, passando por diminuição das distâncias até menores custos. ${ }^{1}$

\footnotetext{
${ }^{1}$ https://www.gov.br/pt-br/noticias/financas-impostos-e-gestao-publica/2019/12/transformacao-digital-traz-economiza-
} de-tempo-e-recursos 
A digitalização no ambiente público se iniciou em 1957 quando o primeiro computador do Brasil foi comprado pelo governo do estado de São Paulo com o objetivo de modernizar o sistema de cobrança de contas do Departamento de Águas e Esgotos. O órgão, recém-criado, lidava com as dificuldades de abastecer a capital e outras cidades da região metropolitana, em um período em que a população urbana crescia em progressão geométrica. ${ }^{2}$ Hoje, dos quase 4,5 mil serviços oferecidos pela administração pública brasileira para cidadãos e empresas, cerca de 3 mil já possuem trâmite totalmente digital e podem ser acessados pelo computador ou por smartphones (Brasil, 2021). No meio privado, não se sabe ao certo quando, mas essa mudança de paradigma se iniciou bem antes. O fato é que a digitalização em massa, não só no meio privado mas também no meio público, está impondo novos desafios à atuação das organizações. Os desafios se tornaram ainda mais evidentes com a aceleração deste processo imposta pela pandemia do vírus COVID-19.

A proliferação de tecnologias de acesso popular, engajamento social e mídias digitais revolucionaram a forma como as pessoas se comunicam, se informam, trabalham, fazem compras, realizam transações bancárias, participam da sociedade e interagem com os governos. Esse processo de digitalização demanda igualmente uma transformação digital nos serviços oferecidos por empresas, instituições e setores públicos. A Estratégia Brasileira de Transformação Digital (E-digital) ${ }^{3}$ visa proporcionar ferramentas para uma profunda transformação na atuação do próprio governo, na competitividade e produtividade das empresas, assim como na capacitação e inclusão na sociedade, para que todos possam se desenvolver e prosperar [Brasil, 2018]. Um dos eixos desta estratégia é em torno da Cidadania digital. A garantia do pleno exercício da cidadania no mundo digital. O objetivo é tornar o governo mais dinâmico, mais próximo da sociedade e mais eficiente facilitando a vida do cidadão. Para apoiar estas políticas públicas, existem três grandes linhas orientadoras, sendo o aumento da transparência; a ampliação da participação social em políticas públicas, e a criação de melhores serviços públicos em formato digital.

Não só no meio público mas também no privado, as organizações têm discutido, planejado e algumas já estão implantando e usando tecnologias para internet das coisas (IoT), conectividade, Big Data, Inteligência Artificial, computação em nuvem, gerando transformações nos seus processos de trabalho, cultura e relações.

O fato é que para garantir a introdução de grandes volumes de tecnologia da informação e comunicação, que sejam amplamente utilizadas pelas partes interessadas, de forma eficaz e eficiente, é necessário transformar essas ações em um pensamento estratégico que envolve reavaliar modelos de negócio, modelos produtivos e modelos de comunicação. É necessário transformar digitalmente uma organização e não somente digitalizar processos.

O termo Transformação Digital surge para propor discussões e abordagens que repensem os modelos organizacionais através da introdução de tecnologias da informação e comunicação (TIC). Este é um tema complexo, pela sua natureza

\footnotetext{
${ }^{2}$ https://brazillab.org.br/noticias/exame-e-o-fim-da-burocracia-como-a-digitalizacao-de-servicos-publicos-avanca ${ }^{3} \mathrm{https} / / /$ www.gov.br/mcti/pt-br/centrais-de-conteudo/comunicados-mcti/estrategia-digital-brasileira/estrategiadigital.p df
} 
multidimensional (desde o nível estratégico até o chão de fábrica) e multidisciplinar (permeia todas as áreas de domínio das organizações). Por esta razão não existe uma definição comum e diferentes visões sobre o tema coexistem, nas quais uma ampla gama de conceitos, dimensões e dinâmicas concorrem e geram um panorama de pesquisa altamente fragmentado [Appio et al., 2021]. Uma coisa que eles têm em comum: é necessário transformar as TICs em vantagem competitiva (ou benefício público). Os desafios são inúmeros, em diversas áreas de domínio, como era de se esperar.

O desafio que queremos abordar nessa discussão está no fato de que escalar o acesso a dados e informações, a solicitação e acompanhamento de serviços e as relações de comunicação de forma digital e (na maioria das vezes) assíncrona tem requerido crescente transparência das informações e do seu fluxo de transformação. O fato é que a transparência, ou a falta dela, tem estado no topo das agendas públicas e também das privadas. Sua importância tem sido realçada com a crescente demanda por serviços digitais assíncronos, e o holofote tem sido colocado principalmente na oferta de serviços públicos através de software. Este é, inclusive, um dos objetivos do E-Digital. Claro que transparência organizacional (ou no ambiente público, a chamada transparência pública) é uma demanda anterior ao pensamento de transformação digital das organizações, como, por exemplo, a publicação da Lei 12.527, chamada Lei de Acesso à Informação, datada de 18 de novembro de 2011. O que acontece é que todo esse processo tecnológico que permitiu aumentar e disseminar mais rapidamente o acesso a dados e informações colocou um holofote sobre o tema e pontuou a necessidade de acelerar a implantação de mecanismos que o garanta.

Transparência pode ser definida como a característica que possibilita ao usuário acessar, entender e ter facilidade e qualidade de uso destas informações [Cappelli; Leite, 2008]. O acesso à informação permite criar uma sociedade democrática com cidadãos participativos, fornecendo-lhes ferramentas para compreender e utilizar a informação e estimulando um pensamento crítico sobre as informações e serviços prestados. Um ponto positivo é que temos visto disponível no contexto público uma abundância de portais de serviços, dados e informações geradas continuamente sobre finanças, saúde, desenvolvimento humano, entre outros [Barcellos, 2017].

Contudo, tais informações públicas são de pouco ou nenhum proveito a menos que os cidadãos entendam o que elas significam [Song; Lee, 2016]. Esse entendimento se faz ainda mais necessário, visto que o governo é o agente que regula a vida social [Layne; Lee, 2001]. E, na prática, apenas um pequeno número de cidadãos se torna capaz de entender dados e informações e fazer uso deles [Park; Gil-Garcia, 2017]. Então, apesar de possibilitar o acesso ser um dos focos principais da agenda pública, este é apenas o primeiro passo, mas, não o único, para que uma informação alcance a transparência.

De fato, como aponta a definição de transparência, para as pessoas usarem efetivamente serviços e se apropriarem de dados e informações que ajudem a fomentar uma participação ativa, principalmente no ambiente público, deve além de dar acesso às informações precisam ser apresentadas de forma que possam ser entendidas. Acontece que no Brasil, um dos desafios é o alto nível de brasileiros iletrados e desfavorecidos 
digitalmente com difícil compreensão das informações. Segundo o Indicador de Analfabetismo Funcional [INAF, 2018], 63\% da população brasileira está abaixo da classificação proficiente ou intermediária para a competência de entendimento em informações simples. A cada 10 brasileiros, 3 têm muita dificuldade para usar a leitura e a escrita, comparar ou avaliar informações.

Uma técnica que favorece o entendimento para uma efetiva transparência, e com isso é uma ferramenta de apoio à transformação digital: a Linguagem Simples (Plain Language $)^{4}$. Essa linguagem faz parte de um movimento cujo foco principal é fazer com que o leitor encontre rapidamente a informação que precisa, consiga entender o que foi encontrado e faça uso dela com facilidade. Ela surgiu em sociedades de língua inglesa na década de 70. Ganhou impulso porque teve apoio de associações de defesa do consumidor, funcionários públicos e pessoas da área do Direito insatisfeitas com uma comunicação complexa. Mesmo não tendo um padrão no início, o movimento foi se espalhando devido à percepção de sua importância.

Percebemos nesse movimento a discussão sobre como oferecer mecanismos para ajudar as pessoas a entender melhor as informações e com isso cumprir de modo mais fácil e rápido suas tarefas ou utilizar serviços (públicos e privados) corretamente [Barboza, 2010]. A Linguagem Simples apoia os leitores a entender o mundo ao seu redor, especialmente aqueles com pouca (ou nenhuma) alfabetização. E isso se dá através da adaptação de documentos, gráficos, figuras, modelos de processos, modelos organizacionais, websites e interfaces de sistemas.

Nosso propósito neste capítulo é: introduzir os conceitos de Transformação Digital, Transparência, Entendimento e Linguagem Simples mostrando o forte relacionamento entre eles; Fornecer um panorama das principais ações em Linguagem Simples; e Apresentar as diretrizes da Linguagem Simples, definidas do Federal Plain Language Guidelines ${ }^{5}$.

Este capítulo está organizado da seguinte forma: A Seção 3.2 apresenta os fundamentos teóricos do tema. Em seguida destacamos as principais ações na Seção 3.3. Uma descrição das práticas apresentadas no Federal Plain Language Guidelines consta na Seção 3.4. Concluímos na Seção 3.5, seguido das referências utilizadas neste capítulo.

\subsection{Fundamentação Teórica}

\subsubsection{Transformação Digital}

Transformações Organizacionais são constantes e necessárias para evolução dos negócios privados e públicos. $\mathrm{E}$ a capacidade de se transformar e se adaptar às novas demandas determina quais organizações vão se destacar. Este tema não é novidade quando discutido pela comunidade que trabalha com os temas de gestão e administração, porém a introdução, quase que obrigatória, do elemento TIC neste contexto, colocou uma nova variável neste ambiente conhecidamente desafiador que

\footnotetext{
${ }^{4}$ https://plainlanguagenetwork.org/plain-language/what-is-plain-language/

${ }^{5}$ https://www.plainlanguage.gov/guidelines/
} 
precisa ser equacionada. $\mathrm{O}$ avanço crescente das novas tecnologias digitais, $\mathrm{o}$ dinamismo dos mercados e a demanda por se tornar presente em todos os lugares e para todos, torna crítica a consideração de TIC como elemento transformador de modelos de negócio e não "mero" mecanismo de digitalização de dados, informações e formulários.

Neste sentido, as ações de TIC deixam de ser vistas como processos de suporte às organizações para serem consideradas nas discussões estratégicas [Collins et al., 2014] de avaliação de mercado, direcionamento, definição de táticas operacionais e como as TIC podem potencializar e inclusive definir como os modelos negociais, de comunicação e vendas serão desenvolvidos e implantados.

Claro que este tema tão complexo, multidimensional e interdisciplinar gera uma pluralidade de definições, abordagens e modelos. De fato, houve um aumento significativo de publicações acadêmicas e de mercado já percebida por Henriette et al. (2015). Diversos autores acadêmicos discutem e evoluem definições sobre o tema, desde uma visão puramente técnica/tecnológica [Resnick, 2002] até as definições que incorporam pensamento estratégico e de transformação do negócio através de aumento da capacidade digital [Sandegberg et al., 2014] [Kane, 2017] [Morakanyane et al., 2017] [Macalintal; Chepkasova, 2017].

Os quatro fatores-chave de sucesso que Laudon e Laudon (2016) apontam como base para conduzir a Transformação Digital nas organizações são as pessoas, os processos, as tecnologias e a cultura. Indo mais além, de acordo com Rogers (2016) existem cinco domínios associados à transformação digital que devem ser observados e transformados de forma integrada: os (tipos de) clientes que a organização tem e quer ter; os níveis de concorrência e cooperação que uma organização tem e quer ter com outras de seu mesmo nicho; a forma como a organização trata e manipula dados e informações; a forma como a organização promove inovação; e a proposta de valor que a organização oferece aos seus clientes.

Explorando a combinação desses elementos estudados e pensando no direcionamento de ações para promover a Transformação Digital nas organizações, segundo estudo realizado por Tadeu et al. (2018), os autores identificaram dez dimensões que podem ser consideradas dentro do contexto da transformação digital:

- Estratégia Digital: as organizações precisam definir os objetivos digitais que foquem nas transformações dos seus negócios e pensar neles de forma integral e não em ações isoladas.

- Tecnologias Digitais: as organizações precisam analisar e decidir sobre quais tecnologias utilizar para implementar suas estratégias digitais e gerar valor. Não escolha IoT, IA, Big Data, 3D, etc sem antes avaliar que valor podem gerar para os seus negócios.

- Capacidade Analítica: as organizações precisam desenvolver forte capacidade analítica, e em saber tratar de forma inteligente seus dados e informações para obter ganhos e gerar valor. Aqui falamos de organização, entendimento, inteligência, disponibilidade e transparência.

- Relacionamento com clientes: as organizações precisam migrar suas formas de comunicação, desde o primeiro contato ou pré-venda até o relacionamento pós-venda. E as novas TIC têm o poder de ajudar as empresas a transformar e 
melhorar essa comunicação e interagir de forma mais inteligente e interessante com o cliente/cidadão.

- Relacionamento em rede: as organizações precisam estender suas ações de transformação digital aos seus parceiros de negócio, sejam fornecedores, governos, universidades, startups, fundos de investimento, etc. Essa integração e transparência desenvolvem cadeias mais responsivas e eficientes.

- Estrutura organizacional e processos digitais: as organizações precisam reformular toda sua estrutura organizacional e processos de trabalho, em todos os níveis, para entrar de cabeça na transformação digital, a começar por aplicar internamente todas as transformações digitais que envolvem automação de processos, comunicações, análise de dados, transparência interna e estruturas flexíveis voltadas para geração de valor através do uso de recursos digitais.

- Cultura e pessoas: a transformação digital demanda grandes mudanças culturais no sentido de promover e demandar mais colaboração, orientação a inovação e decisões orientadas por dados e fatos. Isso requer revisão da formação das pessoas para essa mudança de paradigma, provimento de fluência digital e forte liderança para criar e fortalecer essa nova cultura digital.

- Riscos e investimentos: a transformação digital oferece mecanismos robustos de suporte à gestão de riscos baseados em profunda e sólida análise contínua de dados. Isso abre espaço para promoção de inovações mais ousadas, porém pensadas em cima de decisões melhor fundamentadas e aumenta a segurança dos investidores.

- Aspectos legais e éticos: as organizações precisam entender quais mudanças de paradigma a transformação digital e as novas TIC trazem para as mudanças dos modelos organizacionais e os possíveis impactos legais que isso pode trazer e se precaver.

- Novos modelos de negócios digitais: uma vez iniciada a bem conduzida a transformação digital novos modelos de negócio digitais podem surgir. As organizações, através de mecanismos de inovação, devem estar atentas e buscando oportunidade que as novas TIC podem trazer para expandir e (re)transformar seus negócios.

Em Dias (2019), o autor faz uma breve discussão de seis frameworks que propõem caminhos a serem conduzidos para uma ou mais das dimensões citadas.

\subsubsection{A Lei do Governo Digital}

Em 29 de março de 2021 foi publicada a Lei 14.129 que "dispõe sobre princípios, regras e instrumentos para o Governo Digital e para o aumento da eficiência pública". Esta lei estabelece regras e instrumentos para o aumento da eficiência da Administração Pública, especialmente por meio da inovação, da transformação digital e da participação dos cidadãos.

Segundo o Ministério da Economia ${ }^{6}$, "Com o objetivo de ampliar a oferta de soluções digitais e facilitar a vida dos brasileiros, a lei institui, entre outras diretrizes:

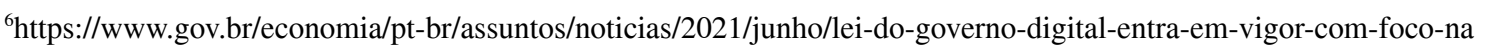
-eficiencia-e-inovacao 
serviços digitais acessíveis por dispositivos móveis (como o aplicativo Meu INSS e a Carteira de Trabalho Digital); uso de plataforma única de acesso a informações e serviços, o gov.br; estímulo às assinaturas eletrônicas nas interações entre órgãos públicos e cidadãos (assinatura avançada nas juntas comerciais, por exemplo); fortalecimento da transparência e do uso de dados abertos pelo governo; além da aplicação da tecnologia para otimizar processos de trabalho da Administração Pública".

Um dos grandes destaques da lei é o estabelecimento de uma plataforma única de acesso pelo cidadão, que por si só, já traz diversos dos desafios de transformação digital já citados e estão sendo enfrentados pelos diversos órgãos de governos em todos os poderes e esferas.

Ao falar de transparência e linguagem simples destacamos alguns trechos que a lei aborda e demanda no Artigo $2^{\circ}$ :

- "simplificação da relação do poder público com a sociedade"

- "a disponibilização em plataforma única do acesso às informações e aos serviços públicos"

- "a transparência na execução dos serviços públicos e o monitoramento da qualidade desses serviços"

- "o incentivo à participação social no controle e na fiscalização da administração pública"

- "o uso de linguagem clara e compreensível a qualquer cidadão"

- "a simplificação dos procedimentos de solicitação, oferta e acompanhamento dos serviços públicos, com foco na universalização do acesso e no autosserviço"

- "a promoção de dados abertos"

Estes trechos deixam claro, mais uma vez, como a transformação digital requer a implantação de mecanismos de transparência e comunicação clara e simples com os cidadãos brasileiros. Em suma, a Lei Do Governo Digital representa um importante passo para a universalização do acesso aos serviços públicos e para criar o conceito de governo como um todo e para todos.

\subsubsection{Transparência}

A ideia de "transparência" possui múltiplos sentidos em diversas áreas. Cappelli (2009) agregaram várias características que compõem o termo para o contexto organizacional. Aspectos como a acessibilidade, usabilidade, entendimento e auditabilidade agregam clareza às informações. Com isso, definiram-se os denominados degraus para a transparência, conforme a Figura 1, um modo de institucionalizar esse conjunto de características associadas em produtos e serviços. 


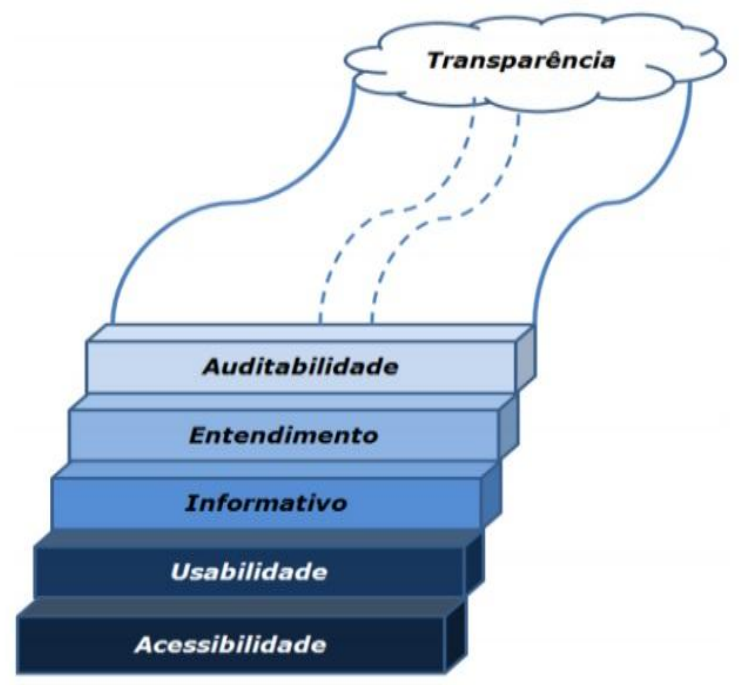

Figura 3.1. Degraus da Transparência [Cappelli, 2009]

A construção do conceito de transparência é feito através de requisitos que se relacionam, atuando como degraus para um nível mais elevado. Em outros termos, para termos uma informação transparente é preciso que anteriormente ela seja entendível. De igual forma para ser entendida deve estar acessível e da mesma maneira que sua representação seja simples, fácil e assim sucessivamente. Todas as interações entre os aspectos favorecem ou influenciam na obtenção da transparência total. Mesmo que, na prática, não haja impedimento de determinada organização atingir pontos de um nível superior dos degraus deixando de cumprir outros de um grau anterior.

Essa estrutura de influência de características de qualidade é mapeada pelos autores em um grafo, conforme a Figura 2. Nele se estende cada conceito em ações a serem implantadas nas organizações conforme o nível de satisfação desejado. Como resultado, temos a formalização do conceito de transparência da informação de acordo com Cappelli (2009) como a característica que possibilita ao cidadão não só acessar, mas obter facilidade de uso, qualidade de conteúdo, entendimento e auditoria às informações de seu interesse, sob a tutela de centros de autoridade. 


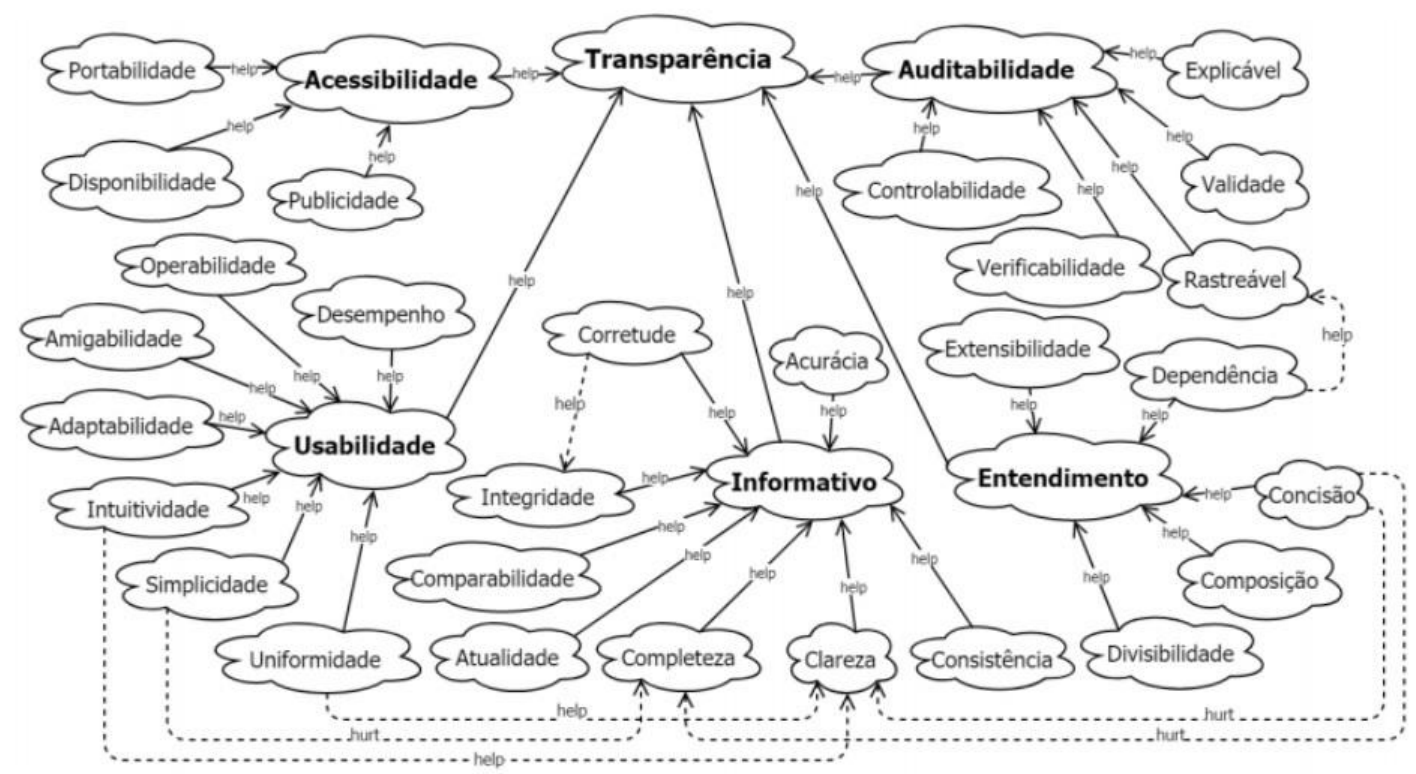

Figura 3.2. Grafo de características da Transparência. [Cappelli, 2009]

\subsubsection{Entendimento}

Esta característica na definição de transparência de Cappelli (2009) se apresenta como um dos pontos mais importantes no trato com o cidadão. Apesar de diversas leis se preocuparem bastante com dar acesso, e garantir o uso, além claro de que os dados tenham qualidade, não se percebe ainda um estímulo a garantir que as informações apresentadas sejam de fato entendidas pela sociedade. O que nos leva a outro problema dado que se o cidadão não entende ele não faz uso e consequentemente não participa de discussões e decisões. O nível do entendimento é uma característica, que segundo Cappelli e Leite (2008) se refere à capacidade de alcançar o significado e o sentido. Ainda que os demais aspectos sejam necessários para o cidadão ter transparência de informações, o entendimento das informações é que fará com que ele de fato se aproprie das mesmas e consiga fazer uso. Para isso precisamos cada vez mais de mecanismos que propiciem este entendimento e a Linguagem Simples é um destes.

\subsubsection{Linguagem Simples}

Linguagem simples é uma das traduções do termo em inglês "Plain Language". Podemos ainda traduzir como Linguagem Clara ou Linguagem Cidadã. O conceito surgiu devido à necessidade de facilitar o entendimento da informação, principalmente aquelas que as organizações apresentam à sociedade. Na década de 1970, um movimento mundial foi iniciado de modo a consolidar orientações para a escrita e a organização visual da informação. Desde então, a prática de Linguagem Simples se disseminou por diversos países. Ao longo deste tempo também nasceram algumas associações e uma Federação que criaram juntas o Federal Plain Language Guidelines, 
que contém um corpo de conhecimento sobre as melhores práticas indicadas pela Linguagem Simples. Neste são apresentadas diretrizes e recomendações para apoiar uma escrita com mais clareza e objetividade. Esta Federação definiu também três princípios para esta Linguagem, indicando que uma comunicação está em linguagem simples quando a escrita, a organização, o design e todo e qualquer outro elemento utilizado para apresentar informação sejam tão claros que o público-alvo consiga encontrar facilmente o que procura, compreender o que encontrou e usar essa informação. Seguimos com essa declaração pela sua abrangência, conceituando o objetivo da linguagem na comunicação de forma ampla, não apenas textual. Apesar da escrita ser o principal meio de aplicação da técnica.

A lei da redação simples (Plain Writing Act) [Gov Info, 2010] nos Estados Unidos sancionada em 2010 estabelecendo que os documentos governamentais emitidos ao público fossem redigidos de forma clara e a política de comunicação do governo canadense que institui também o uso da Linguagem Simples são iniciativas proeminentes na parte norte-americana. As ações oficiais da União Europeia são encontradas no serviço de publicações como a distribuição de manuais de como escrever claramente. Na América Latina o governo colombiano desponta com um Programa Nacional de Serviços ao Cidadão desde 2013 estabelecendo a Linguagem Clara como uma das prioridades da administração pública. Guias, métodos e seminários são divulgados e já foram traduzidos mais de 150 documentos de alto impacto.

Já as iniciativas brasileiras têm referências explícitas sobre a aplicação da Linguagem Simples em websites governamentais brasileiros. A rigor, não existe uma diretriz definida sobre este tema a não ser por citações à Lei de Acesso à Informação, nos respectivos e obrigatórios portais de transparência. $\mathrm{O}$ estado de São Paulo vai à vanguarda divulgando ações para elaboração de uma linguagem mais clara para tradução de suas informações serem mais acessíveis à compreensão do cidadão comum. Contudo, independente dos esforços, Fischer et al. (2019) demonstram que textos essenciais de benefícios do governo federal tem alto grau de dificuldade para leitura seja pela análise textual manual ou automatizada com métricas geradas por ferramentas como o Coh-Metrix-Port 2.0 que utiliza de lógica para criar/identificar o coeficiente de dificuldade do texto como, por exemplo:

- Índice de legibilidade - correlação entre tamanhos médios de palavras, sentenças e a facilidade de leitura

- Sílabas por palavra de conteúdo - número médio de sílabas em substantivos, verbos, adjetivos e advérbios

- Modificadores por sintagma - média de número de advérbios, adjetivos e artigos que participam de um sintagma.

A Linguagem Simples é projetada para comunicar precisamente as informações para o público pretendido, com documentos claros e concisos [Barboza, 2010]. A organização norte-americana FDA (Food and Drug Administration) apresenta muitos benefícios que a experiência com a Linguagem Simples oferece, entre eles: (i) Melhorar a compreensão pública das comunicações do governo; (ii) Economizar dinheiro e aumentar a eficiência; (iii) Reduzir a necessidade de esclarecimento público; (iv) 
Diminuir os recursos gastos com fiscalização; (v) Minimizar erros cometidos e o esforço para corrigi-los.

Shumskaya (2019) compila uma série de argumentos contra ideias de que a Linguagem Simples é apenas um conjunto de regras engessadas para tornar um texto mais curto e infantil e de que não existem provas concretas de sua eficácia. $\mathrm{O}$ trabalho destaca com veemência a linguagem como uma ferramenta importante de capacitação dos cidadãos para tomar decisões conscientes e informadas. Reforçando sua eficácia e garantia de melhorias na comunicação com o seu uso.

Apesar de toda a sua contribuição, ainda existem muitas oportunidades de trabalho a partir deste conhecimento disponibilizado. Quanto à dinâmica escrita, a Linguagem Simples oferece métodos para melhorar a inteligibilidade, entretanto no carácter visual ainda pode ser bastante aprofundada. A partir do que diz a própria definição da linguagem, que além da escrita do texto, a estrutura e o design também devem se apresentar de forma melhor compreensível, pouco se encontra no corpo da própria linguagem sobre o uso de elementos visuais. Estes outros recursos se tornam muito importantes por serem amplamente integrados nas comunicações, justamente pela sua fácil compreensão e carácter atrativo. Identificamos também que a mesma pode se aprofundar a oferecer método que abrange o tópico de visualização, como uma das áreas de fundamentação teórica para o uso de imagens para o entendimento de dados e informações [Oliveira, et al., 2021].

Outro ponto importante que trazemos são as formas como esta linguagem pode ser aplicada. Citamos aqui 4 usos para a mesma:

- Adaptação de textos, modelos de processo, modelos de regras, planejamentos e objetivos, documentos, websites, interfaces de sistemas.

- Organização de informação em repositórios, metadados, modelos conceituais.

- Treinamentos e Mentoria para transferência de conhecimento.

- Adaptação e Desenvolvimento de ferramentas para suporte e automação do uso.

\subsection{Principais Ações em Linguagem Simples}

$\mathrm{Na}$ Linguagem Simples a relevância dos resultados é demonstrada pelas inúmeras iniciativas, públicas e privadas, com intuito de fomentar e aplicar o uso desta linguagem no Brasil e no Mundo. Destacam-se: 


\subsubsection{Ações Internacionais}

- Plain Language Association International $^{7}$ (PLAIN) é uma organização canadense sem fins lucrativos que reúne defensores da linguagem simples e profissionais de todo o mundo em mais de 30 países que trabalham em comunicação clara em pelo menos 15 idiomas.

- Clarity International ${ }^{8}$ é uma organização britânica sem fins lucrativos que reúne profissionais empenhados em promover uma linguagem jurídica simples. Possui representantes oficiais em cerca de 50 países que defendem o uso de linguagem jurídica simples no lugar do "juridiquês".

- Center for Plain Language é uma organização norte-americana composta por profissionais de diversas áreas como acadêmicos, consultores, organizações de saúde e a comunidade de negócios com a missão de criar uma cultura de clareza onde com uma comunicação clara as pessoas e organizações possam prosperar.

- International Plain Language Federation ${ }^{10}$ coordena as ações conjuntas das três organizações citadas anteriormente para promover o uso e a prática da linguagem simples.

- The Plain Language Action and Information Network ${ }^{11}$ é uma plataforma mantida por funcionários do governo norte-americano. Seu objetivo é difundir o uso da linguagem simples em agências e órgãos estatais.

- Plain English Campaign ${ }^{12}$ é uma organização britânica que oferece serviços de edição e análise de textos para linguagem simples e é responsável pelo selo Crystal Mark para documentos de compreensão fácil.

- Plain Language Comission ${ }^{13}$ é uma organização britânica que oferece serviços de edição de textos em linguagem simples e cursos no tema. Criou a certificação Clear English Standard.

- Plain English Foundation ${ }^{14}$ é uma fundação australiana que oferece consultorias e treinamentos em linguagem simples.

- Simplification Centre ${ }^{15}$ é uma organização britânica sem fins lucrativos que promove linguagem simples com foco principal nas áreas da saúde, direito e governo.

\footnotetext{
${ }^{7} \mathrm{https}: / /$ plainlanguagenetwork.org/

${ }^{8} \mathrm{http}$ ///www.clarity-international.org/

${ }^{9}$ https://centerforplainlanguage.org/

${ }^{10} \mathrm{https}: / /$ www.iplfederation.org/

${ }^{11} \mathrm{https} / / / \mathrm{www}$.plainlanguage.gov/

$12 \mathrm{http} / / / \mathrm{www}$.plainenglish.co.uk/

${ }^{13}$ https://www.clearest.co.uk/

${ }^{14} \mathrm{https}: / /$ www.clearest.co.uk/about

${ }^{15} \mathrm{https} / / / \mathrm{www}$.simplificationcentre.org.uk/
} 
- Red de Lenguaje Claro ${ }^{16}$ é uma organização chilena que reúne 7 instituições públicas com o objetivo de trabalhar em conjunto na implementação de ações que visem gerar iniciativas, projetos e medidas que promovam, divulguem e facilitem o uso da linguagem clara.

\subsubsection{Ações Nacionais}

- Guia de Edição de Serviços do Gov.br ${ }^{17}$ é um guia desenvolvido pelo Governo Federal sobre como melhorar o texto de um serviço utilizando linguagem simples. Ele contém diretrizes e recomendações para o uso de linguagem simples para editores do portal do governo federal, auxiliando a manter os textos mais claros e úteis para os usuários desses serviços.

- Projeto Acessibilidade $\mathrm{TT}^{18}$ é um Projeto de pesquisa da Universidade Federal do Rio Grande do Sul que aborda a acessibilidade textual e terminológica

- O Laboratório Interdisciplinar de Linguagem Cidadã ${ }^{19}$ sediado no Rio de Janeiro, congrega pesquisadores atuando em pesquisa teórica e aplicada sobre linguagem cidadã.

- O Programa Municipal de Linguagem Simples da prefeitura de São Paulo ${ }^{20}$, criado em 2019, quer simplificar a linguagem que a Prefeitura de São Paulo usa na comunicação com a população.

- As orientações para Adoção de Linguagem Clara no Portal Governo Aberto $\mathrm{SP}^{21}$, criadas em 2016, oferecem um guia que é parte integrante do projeto de cooperação entre o Governo do Estado de São Paulo e o Reino Unido.

- O Laboratório de Inovação e Dados do Governo do Estado do Ceará22 (Iris Lab Gov) foi criado com a proposta de fomentar e ampliar a inovação no setor público que tem como um de objetos de pesquisa e investimento a discussão e implantação da linguagem simples no Estado.

\footnotetext{
${ }^{16}$ http://www.lenguajeclarochile.cl/

${ }^{17} \mathrm{https}$ ///www.gov.br/pt-br/guia-de-edicao-de-servicos-do-gov.br/escrevendo-para-o-seu-usuario

${ }^{18} \mathrm{http}: / /$ www.ufrgs.br/textecc/acessibilidade/

${ }^{19}$ https://linclab.com.br/

${ }^{20} \mathrm{https}$ ///011lab.prefeitura.sp.gov.br/linguagem-simples/inicio

http://www.governoaberto.sp.gov.br/wp-content/uploads/2017/12/orientacoes_para_adocao_linguagem_cl ara_ptBR.pdf

${ }^{22}$ https://www.egp.ce.gov.br/irislabgov/
} 


\subsubsection{Leis Nacionais}

- Lei de Acesso à Informação (Lei 12.527 de 18 de novembro de 2011), determina que todo órgão e entidade pública ofereça o acesso às suas informações utilizando de procedimentos objetivos, ágeis, transparentes, claros e em linguagem de fácil compreensão.

- Lei do Governo Digital (Lei 14.129 de 29 de março de 2021) dispõe sobre princípios, regras e instrumentos para o Governo Digital e para o aumento da eficiência pública.

- Lei 13.460 de 26 de junho de 2017 dispõe sobre participação, proteção e defesa dos direitos do usuário dos serviços públicos da administração pública. Esta lei regulamenta a Carta de Serviços, onde cada município deverá elaborar a sua carta com informações claras e precisas, tendo que dispor em locais de fácil acesso, tais como o portal institucional e o local onde os serviços serão prestados.

\subsection{Práticas para implementar a Linguagem Simples}

Dado que o objetivo principal da Linguagem Simples é facilitar a compreensão, a localização e o uso das informações, podemos dizer que certamente ela é base para a transparência e consequentemente o ponto inicial para a participação cidadã. No caso da transparência podemos dizer ainda que garante que a sociedade acesse facilmente os dados emitidos pelos órgãos do governo e acompanhe, de modo mais atuante, a gestão pública. Somente a clareza e conhecimento das informações permite um cidadão engajado e participativo.

Para isso faz-se necessário que as organizações, principalmente as da esfera pública, estejam preparadas para o uso desta linguagem. Textos com jargões e termos técnicos, elaborados de maneira complexa e com palavras de difícil entendimento apenas geram desinteresse e confusão. Muitas vezes o cidadão precisa de uma terceira pessoa que possa lhe explicar o que está sendo dito com aquela determinada informação. Junte-se a isso a tradicional forma de escrita dos governos que são extremamente burocráticas, enfraquecendo a comunicação entre o poder público e os cidadãos que ficam muitas vezes sem entender seus direitos e deveres apesar de isso ser um direito constitucional.

Deve-se considerar que uma Linguagem Simples também torna a comunicação mais inclusiva, o que promove acessibilidade. Para entender melhor as práticas da Linguagem Simples e poder aplicá-las é importante ter domínio do conteúdo apresentado no Federal Plain Language Guidelines. Este guia, como já citado anteriormente, está sob a tutela de uma federação sendo organizado e mantido por organizações ligadas a esta federação. Este guia é estruturado em 5 grandes blocos de conteúdo como apresentado na Figura 3. Neste trabalho detalharemos e mostraremos através de alguns exemplos as principais práticas definidas nos três primeiros blocos. 

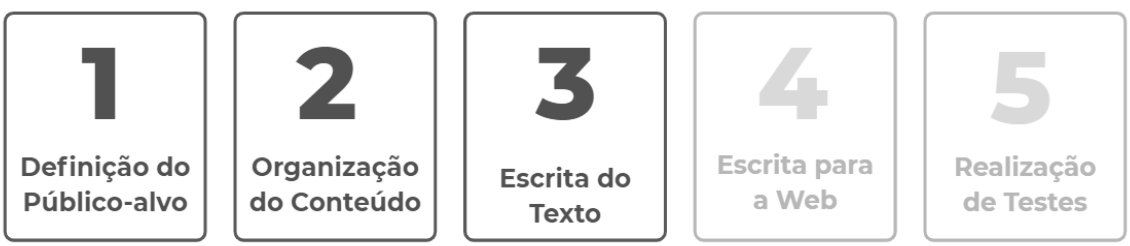

Figura 3.3. Conteúdo do Federal Plain Language Guidelines. Fonte: Os Autores.

\subsubsection{Definição do Público-alvo}

Esta prática indica que devemos buscar conhecer o público alvo da informação que estamos tentando transmitir, entender o quanto ele já sabe sobre o tema, o que mais ele precisa saber e que perguntas ele faria sobre aquele conjunto de informações. Além disso, é importante pensar qual será o melhor resultado a ser apresentado e como devo me expressar para apresentar este resultado dessa forma. Esta prática se divide em duas diretrizes: como escrever para sua audiência e como tratar diferentes audiências.

\subsubsection{Como Escrever para sua Audiência}

A técnica de definir Personas pode ajudar neste caso. Persona é a representação fictícia do seu cliente típico. Ela é baseada em: dados reais sobre o comportamento, características demográficas, histórias pessoais, motivações, objetivos, desafios e preocupações. A Figura 4 apresenta um exemplo e a Tabela 1 apresenta um exemplo de uso da Linguagem Simples adaptada a uma possível persona definida.

\section{Exemplo de Persona}

Paulo Correa - Técnico de Suporte

Paulo Correa, de 43 anos, trabalhou durante muitos anos consertando e configurando computadores. Atualmente, trabalha na universidade AprendaMais, configurando PCs e as contas de alunos de cada turma. Ele faz um curso de administração de redes, mas prefere aprender fazendo do que assistindo aulas ou lendo manuais. Quando tem alguma dúvida, ele faz uma busca na Internet por informações que lhe ajudem a resolver os seus problemas. Usuário "das antigas", Paulo prefere utilizar linguagem de comando do que assistentes em interface gráfica, pois acredita que assim seja mais eficiente. Sempre que uma tarefa se repete com freqüência, ele tenta elaborar um script ou fazer uma configuração que acelere seu trabalho.

Todo início de período, Paulo precisa configurar dezenas de contas para cada turma, com diferentes perfis, fornecendo acesso diferenciado para alunos regulares, monitores, instrutores e coordenadores de cada disciplina. Precisa atender aos pedidos dos professores sobre o que deve estar disponível na intranet de cada disciplinas (e.g., material didático, fórum de discussão, recebimento de trabalhos de alunos, cadastramento de notas, pedidos de revisão). Seu maior objetivo é atender aos professores com a maior eficiência possível. Para isso, é importante ele poder acessar o sistema onde quer que esteja, no horário que for, para realizar qualquer tarefa remotamente.

Adaptado de Barbosa e Silva (2010)

Figura 3.4. Exemplo de Persona Adaptado de Barbosa e Silva (2010) 
Tabela 3.1. Exemplo de uso de Persona

\begin{tabular}{|c|c|}
\hline Texto Comum & Texto com Linguagem Simples \\
\hline $\begin{array}{l}\text { "O atendimento para solicitação de } \\
\text { desconto no IPTU residencial será } \\
\text { disponibilizado nas agências regionais ao } \\
\text { público em dias úteis em horário } \\
\text { comercial" }\end{array}$ & $\begin{array}{l}\text { "Se você é dono de uma casa na cidade } \\
\text { de Patópolis e ganha até } 5 \text { salários } \\
\text { mínimos, pode solicitar desconto do } \\
\text { IPTU em qualquer agência municipal de } \\
\text { segunda a sexta das } 09 \mathrm{~h} \text { às } 18 \mathrm{~h} "\end{array}$ \\
\hline
\end{tabular}

\subsubsection{Tratar diferentes audiências}

A depender da quantidade de personas definidas como público-alvo da sua informação, pode ser importante abordar públicos diferentes, separadamente. Muitos conteúdos abordam mais de um público. Conjuntos de informação que misturam elementos destinados a públicos diferentes podem confundir os leitores, pois, ao abordar diferentes públicos no mesmo lugar, você dificulta para cada público encontrar o material que se aplica a eles dificultando que cada público possa cumprir os requisitos para sua necessidade.neste caso o mais indicado é que se usem formas de apresentação de informação ou até mesmo conteúdos diferenciados para as personas ou grupos de personas definidos.

\subsubsection{Organização do Conteúdo}

Organizar conteúdos na maioria das vezes é a chave para o entendimento. Em geral, lemos documentos, analisamos informações ou visitamos sites para obter respostas para nossos problemas ou informações para atender nossas necessidades. Queremos saber como fazer algo ou o que acontece se não fizermos nada. Também queremos obter esse conhecimento o mais rápido possível. Para tal o Federal Plain Language Guidelines sugere algumas práticas para fazer melhor esta organização. Ele aborda 4 diretrizes: atender às necessidades da audiência, falar para uma pessoa e não para um grupo, usar títulos úteis e escrever seções curtas.

\subsubsection{Atender às necessidades da audiência}

Para todo conteúdo que se queira transmitir é importante começar sempre declarando a finalidade do documento e seus resultados. Deve-se eliminar qualquer preenchimento e conteúdo desnecessário e atentar para colocar as informações mais importantes no início da apresentação. Informações básicas (quando necessário) devem ser colocadas no final. Outro ponto bastante importante é que o seu conteúdo deve estar organizado para responder às perguntas que o seu público provavelmente fará. Busque estruturar na ordem em que ele as faria.

Para conjuntos de informação, mas complexos, podem ser criados índices que facilitem a navegação ou a busca direta. No caso de sites, os menus podem também ser um grande aliado para isso. Estes mecanismos ajudam os usuários a seguir e encontrar 
rapidamente as informações de que precisam. Porém, não crie muitos níveis de hierarquia. No caso de documentos recomenda-se que seja no máximo 3.

No caso de um processo ou um serviço, pode-se apresentar as etapas dos mesmos na ordem em vão ser usadas ou executadas. Isso não só facilita o entendimento como também guia o usuário diminuindo a incidência de erros.

Já considerando um conteúdo que possui informações gerais e específicas, coloque as informações gerais em primeiro lugar e as especializadas ou exceções depois. $\mathrm{O}$ que se dirige à maioria dos leitores na maioria das situações deve vir em primeiro lugar.

Se existir mais de um público para a sua informação, procure abordar cada um separadamente. Não é agradável ter que olhar informações destinadas a outro público. Personalização é uma técnica que pode e deve ser utilizada sempre.

\subsubsection{Fale para uma pessoa, não para um grupo}

Um fator bastante importante é falar com quem está lendo a informação. Mesmo que sua comunicação vá atingir um milhão de pessoas, lembre que você está falando com a única pessoa que o está lendo. Não dar atenção a isso pode gerar confusão se uma determinada ação que está sendo descrita deve ser realizada pela pessoa que lê ou por um grupo. Uma boa prática bastante recomendada é usar "você" para se dirigir ao usuário. O uso do "ele ou ela" pode fazer com que o leitor não perceba que ele é o agente da ação. A tabela 2 ilustra como fazer uso desta prática.

Tabela 3.2. Exemplo de uso de fala direta

\begin{tabular}{|l|l|}
\hline Texto Comum & Texto com Linguagem Simples \\
\hline $\begin{array}{l}\text { Os residentes de Patópolis que buscam } \\
\text { assistência no processo de preenchimento }\end{array}$ & $\begin{array}{l}\text { Se você precisar de ajuda com sua } \\
\text { e envio de sua inscrição podem entrar em } \\
\text { contato com a agência usando o número para a agência usando o } \\
\text { de telefone listado abaixo. }\end{array}$ \\
número abaixo. \\
\hline
\end{tabular}

\subsubsection{Use Títulos úteis}

Uma maneira eficaz de facilitar o entendimento de um conjunto de informações, um sistema, um documento ou até um site é usar títulos auto explicativos e úteis. Existem algumas categorias de títulos:

- Título de perguntas: Muito úteis, mas é necessário perceber quais perguntas o seu público fará. Se essas perguntas são possivelmente conhecidas, use-as como títulos. Elas ajudarão o público a encontrar rapidamente as informações que procuram. Um bom exemplo disso são os FAQs (Frequently Asked Questions) 
que atualmente a maioria das organizações disponibiliza em seus sites reunindo as perguntas mais frequentes feitas e as respostas das mesmas.

- Título de declarações: Define em poucas palavras o que se segue no conteúdo. É sempre uma ótima escolha porque resume bem o que segue.

- Título de Tópicos: São do tipo "Geral", "Aplicativo" e "Escopo". Devemos evitar sempre que possível, pois são vagos e não ajudam a saber o que tem de fato no que segue.

Estruturar primeiramente os títulos seja de um texto, um conjunto de dados ou de um menu pode nos ajudar a perceber a estrutura, verificar se não faltou nada e também nos mostrar possíveis agrupamentos. Em todos os casos citados, os títulos nunca devem ser muito longos. Um máximo de 5 palavras pode ser uma boa prática. A Tabela 3 mostra um exemplo.

Tabela 3.3. Exemplo de títulos úteis

\begin{tabular}{|l|l|}
\hline Texto Comum & Texto com Linguagem Simples \\
\hline $\begin{array}{l}\text { Levantamento de Profissionais da saúde } \\
\text { não vacinados contra COVID-19 }\end{array}$ & $\begin{array}{l}\text { Prefeitura realiza esta semana um } \\
\text { levantamento de trabalhadores da saúde } \\
\text { que ainda não foram vacinados contra a } \\
\text { COVID-19 para escalonar uma nova } \\
\text { etapa de vacinação para este grupo. }\end{array}$ \\
\hline $\begin{array}{l}\text { Transmissão de COVID-19 - Contato } \\
\text { com dinheiro }\end{array}$ & $\begin{array}{l}\text { Você pode pegar COVID-19 através de } \\
\text { diversos elementos de contato, incluindo } \\
\text { moedas e notas de dinheiro. }\end{array}$ \\
\hline
\end{tabular}

\subsubsection{Escrever seções curtas}

Seções curtas dão a sensação de que vamos entender de maneira mais fácil. Seções densas e longas são visualmente desagradáveis e dão a impressão de que a informação é difícil de entender. Para darmos títulos, uma seção curta também nos ajuda, pois, tem apenas um assunto em geral, o que não acontece com seções longas, pois são mais difíceis de resumir. Muitas vezes tratam de mais de um assunto. A Tabela 4 mostra um exemplo. 
Tabela 3.4. Exemplo de seções curtas

\begin{tabular}{|c|c|}
\hline Texto Comum & Texto com Linguagem Simples \\
\hline $\begin{array}{l}\text { O programa tem uma linha telefônica } \\
\text { Punjabi em 604-877-6163 na qual você } \\
\text { pode deixar uma mensagem de correio de } \\
\text { voz para alguém retornar sua chamada (as } \\
\text { chamadas só são retornadas às } \\
\text { sextas-feiras entre } 10 \mathrm{~h} 00 \text { e } 12 \mathrm{~h} 00 \text { ). Além } \\
\text { disso, atendentes de reservas que falam } \\
\text { chinês geralmente estão disponíveis pelo } \\
\text { telefone 1-800-663-9203. Se não houver } \\
\text { um disponível para atender sua chamada, } \\
\text { você será questionado se alguém pode } \\
\text { traduzir em seu nome ou para ligar de } \\
\text { volta quando houver assistência de } \\
\text { tradução disponível. Você também pode } \\
\text { pedir a um membro da família ou amigo } \\
\text { para ajudá-lo com a ligação. }\end{array}$ & $\begin{array}{l}\text { O programa tem uma linha telefônica } \\
\text { Punjabi em 604-877-6163 que você pode } \\
\text { deixar uma mensagem de voz para } \\
\text { alguém retornar sua chamada às } \\
\text { sextas-feiras entre } 10 \mathrm{~h} 00 \text { e } 12 \mathrm{~h} 00 \text {. } \\
\text { Atendentes de reservas que falam chinês } \\
\text { estão disponíveis pelo telefone } \\
\text { 1-800-663-9203. Se não houver um } \\
\text { disponível para atender sua chamada, será } \\
\text { indicado ligar de volta quando houver } \\
\text { tradução disponível. } \\
\text { Você pode pedir a um membro da família } \\
\text { ou amigo para ajudá-lo com a ligação. }\end{array}$ \\
\hline
\end{tabular}

\subsubsection{Escrita do Texto}

A escrita do conteúdo é a terceira prática fundamental. A escolha cuidadosa das palavras, os verbos que devem dizer exatamente o que será feito, o cuidado com as abreviações fazem parte desta prática. Aqui, após termos nos preocupado com a estrutura, temos que nos preocupar com a forma de transmitir o conteúdo. As práticas parecem isoladas, mas não são. As diretrizes de escrita do texto na Linguagem Simples está direcionada para palavras, sentenças e parágrafos.

\subsubsection{Palavras}

A escolha das palavras na escrita do texto é algo muito importante. Podemos dizer que elas são o bloco mais básico do texto. Algumas características devem ser observadas quando estamos escolhendo palavras:

- Concisão: Escolha sempre o menor número de palavras possível para dizer a mesma coisa.

- Precisão: Escolha sempre a melhor palavra para transmitir uma ideia. Buscar sinônimos é sempre uma ótima prática.

- Simplicidade: Se tiver que escolher entre mais de uma palavra com o mesmo significado, escolha a mais simples, a que tem mais oportunidades de ser entendida pela sua audiência.

- Domínio comum: Escolha sempre as palavras de domínio da maior parte do seu público-alvo. 
Outra prática que traz bons resultados é usar a voz ativa. A voz ativa é a voz verbal que indica que o sujeito da oração pratica a ação. E na Linguagem Simples sempre indicamos falar diretamente com quem é o responsável pela ação. Assim sendo ela será sempre a mais indicada.

Quanto aos verbos, use sempre as formas mais simples. O presente do indicativo é o tempo verbal mais recomendado. Verbos ocultos não devem ser utilizados. Em geral, aparecem convertidos em substantivos o que dificulta o entendimento do texto. Além disso, acaba obrigando que exista um verbo extra para completar o sentido da frase. Inca-se então que a conversão de verbos em substantivos seja minimizada o máximo possível.

Outro ponto importante é evitar o uso de jargões ou termos técnicos, legais ou estrangeiros quando existirem outras palavras com mesmo significado que possam substituí-los. Sempre é melhor usar palavras conhecidas da audiência. É importante também evitar ou reduzir ao máximo o uso de abreviações. Muitas vezes para poder entendê-las o leitor terá que repetidamente recorrer a outro local do texto ou da imagem onde esta está explicada. Neste ponto podemos falar também da boa prática de evitar apresentar definições. Em geral, elas são apresentadas no meio do texto, o que gera uma quebra de continuidade da ideia que está sendo apresentada.

$\mathrm{O}$ uso de palavras curtas também é recomendado. Se tiver que escolher entre duas conhecidas pela audiência e que tenham o mesmo significado, opte pela menor. Evite também ter que apresentar sua definição.

Além destas práticas citadas na estrutura das palavras, recomenda-se usar sempre o mesmo termo para se referir a um mesmo objeto. Neste caso podemos exemplificar o termo "patrão" e "empregador" sendo sinônimos, mas que para um público mais leigo pode levar a uma interpretação de que o primeiro tem relação com emprego informal e o segundo com emprego formal. A Tabela 5 nos mostra alguns exemplos.

Tabela 3.5. Alguns exemplos de uso de palavras

\begin{tabular}{|l|l|}
\hline Texto Comum & Texto com Linguagem Simples \\
\hline $\begin{array}{l}\text { Os agendamentos podem ser feitos em } \\
\text { diversos locais em todo o município. }\end{array}$ & $\begin{array}{l}\text { Você pode fazer a marcação em qualquer } \\
\text { local da cidade. }\end{array}$ \\
\hline O relatório foi elaborado por João. & João escreveu o relatório. \\
\hline $\begin{array}{l}\text { Se o paciente sentir dor no peito, suor e e você sentir dor no peito, suor e falta de } \\
\text { falta de ar, deve ligar imediatamente para } \\
190 .\end{array}$ & $\begin{array}{l}\text { Se ligue para 190. } \\
\text { ar, }\end{array}$ \\
\hline $\begin{array}{l}\text { Ao final será solicitado que o cliente dê } \\
\text { seu feedback sobre o serviço. }\end{array}$ & $\begin{array}{l}\text { Ao final pedimos a você que informe seu } \\
\text { grau de satisfação com o serviço. }\end{array}$ \\
\hline
\end{tabular}


Traga sua carteira de identidade e/ou carteira de habilitação.
Traga um dos seguintes documentos:

- Carteira de identidade

- Carteira de habilitação

\subsubsection{Sentenças}

Escolha suas palavras e as organize com cuidado. Comece sempre com a ideia principal. As exceções devem ser tratadas depois. A ordem das palavras é muito importante. Coloque suas palavras com cuidado procurando ser sempre breve.

Não é ruim usar muitos pontos. É melhor escrever frases curtas com uma única ideia, do que longas com várias ideias nela. Isso vai acabar levando para outra boa prática de escrever sentenças também curtas.

A ordem natural das palavras de uma frase é sujeito-verbo-objeto. Busque sempre escrever desta forma. Sempre procure escrever frases completas. Neste caso de estrutura de frases, outro ponto importante são as negativas. Elas devem sempre ser evitadas. Estamos acostumados a pensar e falar positivamente. Negativas tendem a nos confundir. No caso do uso de duplas negativas e exceções isso fica ainda um pouco mais complexo para o entendimento. Quando escrevemos no negativo, colocamos um empecilho no caminho do entendimento do público-alvo. Quando você escreve uma frase contendo dois negativos, eles se cancelam, ou seja, na verdade, ela seria uma afirmativa. A melhor prática então é sempre usar a frase afirmativa, colocando a ideia principal no início e as exceções depois. A Tabela 6 nos mostra alguns exemplos.

Tabela 3.6. Alguns exemplos de sentenças

\begin{tabular}{|l|l|}
\hline Texto Comum & Texto com Linguagem Simples \\
\hline $\begin{array}{l}\text { O treinamento, que contou com a a treinamento foi bem-sucedido: 60 } \\
\text { participação de 60 funcionários e obteve } \\
\text { índices de aprovação acima de 95\%, foi } \\
\text { um grande sucesso. }\end{array}$ & $\begin{array}{l}\text { Ouncionários compareceram e deram } \\
\text { índices de aprovação de mais de 95\%. }\end{array}$ \\
\hline $\begin{array}{l}\text { Nenhum trabalho adicional é necessário } \\
\text { na ausência de uma emergência. }\end{array}$ & $\begin{array}{l}\text { O trabalho adicional só é necessário em } \\
\text { caso de emergência. }\end{array}$ \\
\hline $\begin{array}{l}\text { Todas as pessoas, exceto aqueles com 18 } \\
\text { anos ou mais, devem preencher o } \\
\text { formulário. }\end{array}$ & $\begin{array}{l}\text { Cada pessoa com menos de 18 anos deve } \\
\text { preencher o formulário. }\end{array}$ \\
\hline $\begin{array}{l}\text { Ana encontrou o gerente da loja com o } \\
\text { seu irmão. }\end{array}$ & $\begin{array}{l}\text { Ana encontrou o seu irmão com o gerente } \\
\text { da loja. OU Ana encontrou o gerente da } \\
\text { loja com o irmão dele? }\end{array}$ \\
\hline
\end{tabular}


$\mathrm{O}$ recurso ao Tribunal de Primeira Instância, embora organizado de forma ineficaz, foi, no entanto, apresentado pelo escritório de advogados.
O escritório de advocacia apresentou seu requerimento ao Tribunal de Primeira Instância, apesar da organização ineficaz.

\subsubsection{Parágrafos}

Escreva parágrafos curtos que contenham somente uma ideia. Inicie sempre com uma sentença que define o tópico que vai ser detalhado. Uma frase de tópico pode fornecer uma transição de um parágrafo para outro. Uma palavra ou frase de transição diz claramente ao público-alvo se: (i) o parágrafo se expande no parágrafo seguinte, (ii) se contrasta com ele, (iii) se haverá uma direção completamente diferente. Outro ponto bastante importante é o título do parágrafo. Este deve conter um resumo do mesmo de forma que vá consumir tal informação já tenha um resumo da mesma pelo título. A Tabela 7 nos mostra alguns exemplos.

Tabela 3.7. Alguns exemplos de uso em parágrafos

\begin{tabular}{|l|l|}
\hline Texto Comum & Texto com Linguagem Simples \\
\hline $\begin{array}{l}\text { Quando duas ou mais declarações são } \\
\text { feitas em substituição e uma delas, se }\end{array}$ & $\begin{array}{l}\text { Se uma das partes fez declarações } \\
\text { alternativas, o pedido é suficiente se } \\
\text { feita de forma independente, seria } \\
\text { suficiente, a argumentação não é } \\
\begin{array}{l}\text { insuficiente pela insuficiência de uma ou } \\
\text { mais das declarações alternativas. }\end{array}\end{array}$ \\
\hline
\end{tabular}

\subsubsection{Boas Práticas Gerais}

Além de todas as práticas citadas anteriormente, algumas outras mais gerais também podem ajudar na melhoria do entendimento e na clareza da informação. Aqui temos algumas delas:

- O uso de exemplos pode ajudar seu público-alvo a entender melhor a informação.

- A criação de listas e tabelas pode organizar melhor um texto muito extenso e cheio de itens.

- A inclusão de uma ilustração pode ser mais útil do que uma extensa descrição textual.

- O uso de recursos como negrito e itálico podem ser interessantes para destacar coisas importantes.

- A redução do número de referências cruzadas pode ajudar o consumidor da informação a não se dispersar muito. 


\subsubsection{Boas Práticas acerca do Design}

$\mathrm{Na}$ parte de design da informação outras práticas interessantes podem ser também utilizadas para melhoria do entendimento. A Figura 5 é um exemplo de como o design pode transformar a identidade visual de um elemento de informação. Aqui temos algumas destas boas práticas de design:

- Buscar sempre apresentar informações ordenadas e não muito densas. Em geral, quando não seguimos essa prática criamos uma reação negativa na mente dos usuários.

- Devemos dar bastante atenção ao design da informação. Ele é uma parte importante do desenvolvimento de um documento eficaz. Documentos agradáveis à vista são muito mais fáceis de entender do que os estilos mais tradicionais.

- Sempre que puder deve-se substituir blocos de texto por cabeçalhos, tabelas e listas para criar mais espaços em branco e deixar a apresentação mais leve ao olhar de quem a consome.

- Frases e seções curtas, como recomendado em práticas citadas aqui anteriormente, também dividirão um texto em partes visualmente melhor gerenciáveis.
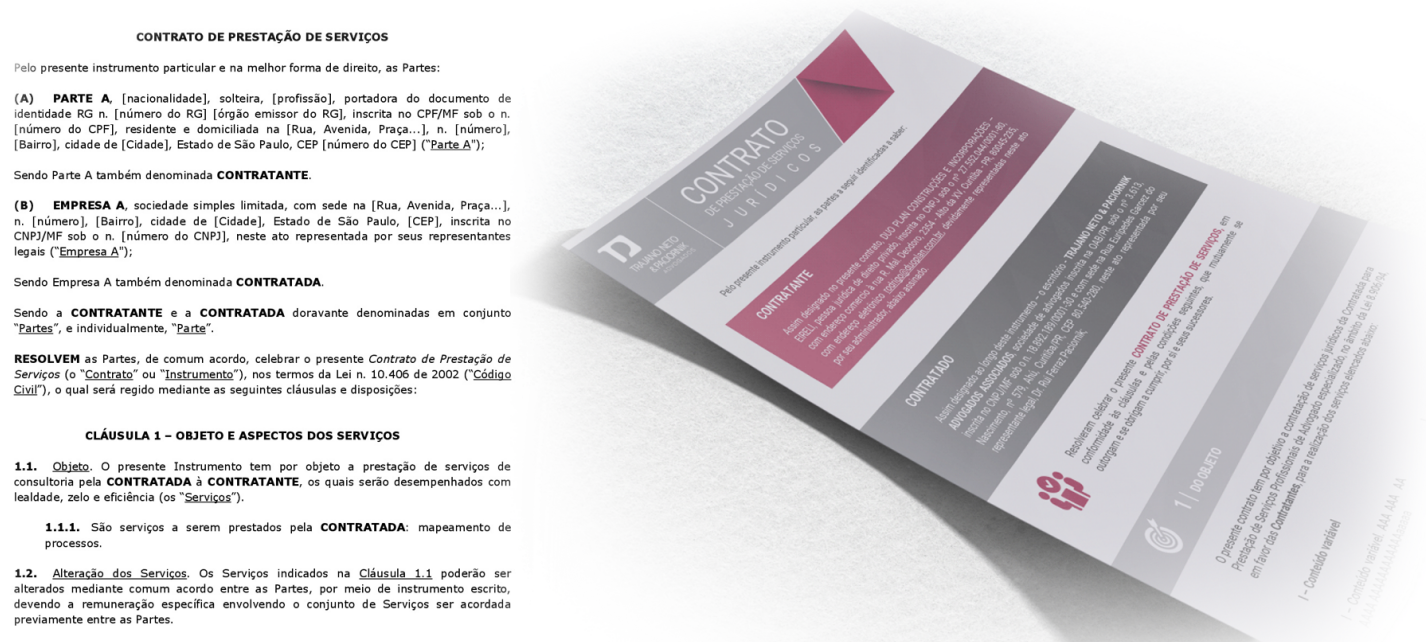

Figura 3.5. Exemplo de contrato com boas práticas de Design [Ribeiro, 2021].

\subsection{Conclusão}

Neste Capítulo apresentamos como a técnica da Linguagem Simples pode apoiar a construção de conteúdos de fácil entendimento. Um requisito necessário para a transparência das informações e seu uso para a transformação digital que vivenciamos. Destacamos os principais conceitos relacionados aos temas, demonstrando o inter relacionamento de cada tópico. No caso de órgãos públicos, por exemplo, a transformação digital promove ferramentas digitais para atuação eficiente do próprio 
governo com participação de toda a sociedade. O foco na transparência é reforçado neste processo para que as pessoas possam usar serviços, dados e informações, ou mais precisamente, que todo esse conteúdo possa ser entendido de fato. A técnica da Linguagem Simples é usada na busca desse objetivo porque favorece o entendimento para uma efetiva transparência, e com isso impulsiona a transformação digital.

Foram apresentadas ainda as principais iniciativas no Brasil e no mundo no uso desta técnica de Linguagem Simples. Como pode ser visto hoje já contamos com diversas organizações que fazem coro na aplicação desta técnica sendo estas, centros de pesquisa, organizações internacionais independentes, universidades e outras, o que nos mostra a importância e magnitude deste movimento, chamado de Plain Language Movement, para garantir à sociedade o direito ao entendimento.

A partir do Federal Plain Language Guidelines apresentamos também as principais diretrizes para uma escrita mais simples. Foram mostradas práticas gerais para organização do texto como: definir o público-alvo adequado, usar bons títulos e escrever seções curtas de conteúdo. Seguindo a discussão para a escrita do texto propriamente dito, repassando orientações sobre as palavras, sentenças e parágrafos. Finalizando com boas práticas gerais sobre o design, o uso de exemplos e representações visuais. Este último, é um caso a parte que exploramos em pesquisas, mas que aqui fica como trabalhos futuros. Os recursos visuais naturalmente exigem menor esforço cognitivo à interpretação humana pelas suas formas. A Linguagem Simples, se propõe a melhorias não apenas no âmbito da escrita de texto, mas na estrutura e no design da informação. Contudo, no Federal Plain Language Guidelines há uma única diretriz que se refere ao uso de imagens para clareza informacional, indicando apenas o uso ilustrativo. Não há nenhuma menção a como se deve construir eficientemente esses recursos visuais. O Federal Plain Language Guidelines, poderia oferecer também um conjunto oficial de orientações para apresentação de informações e seu design em Linguagem Simples. Alguns estudos mais recentes já apontam como isso poderia ser feito.

\section{Referências}

Appio, F. P., Frattini, F., Petruzzelli, A. M., \& Neirotti, P. (2021). Digital transformation and innovation management: A synthesis of existing research and an agenda for future studies.

M., Neirotti, P. (2021). Digital Transformation and Innovation Management: A Synthesis of Existing Research and an Agenda for Future Studies. Journal of Prod Innov Manag, 38(1), pp. 4-20.

Barboza, E. M. F. (2010). A linguagem clara em conteúdos de websites governamentais para promover a acessibilidade a cidadãos com baixo nível de escolaridade. Inc. Soc., Brasília, DF, v. 4 n. 1, pp. 52-66.

Brasil. Mais de $70 \%$ dos serviços públicos brasileiros já são digitais. Agência Brasil. (2021). cos-brasileiros-ja-sao-digitais. Acesso em: 13 agosto de 2021. 
Brasil. Ministério da Ciência, Tecnologia, Inovações e Comunicações (MCTIC). Estratégia Brasileira de Transformação Digital: E-digital. (2018). Disponível em: http://www.mctic.gov.br/mctic/export/sites/institucional/estrategiadigital.pdf. Acesso em: 13 agosto 2021.

Boscarioli, C., Araujo, R.M, Maciel, R.S. (2017). I GranDSIBR: Grand Research Challenges in Information Systems in Brazil 2016-2026. Special Committee on Information Systems. Brazilian Computer Society (SBC). ISBN: [78-85-7669-384-0]. Disponível

https://sol.sbc.org.br/livros/index.php/sbc/catalog/book/28

Barcellos, R. (2017). Avaliação da Qualidade e Interpretabilidade de Visualizações de Dados. (Dissertação de Mestrado, Universidade Federal Fluminense) Niterói. pp. 87.

Cappelli, C., Leite, J. C. S. P. (2008). Transparência de processos organizacionais. II Simpósio Internacional de Transparência nos Negócios, Universidade Federal Fluminense, LATEC, Niterói, RJ, Brasil.

Cappelli, (2009) Uma abordagem para transparência em processos organizacionais utilizando aspectos. Tese de Doutorado. Disponível em: http://www-di.inf.puc-rio.br/ julio/tese-cappelli.pdf

Collin, J., Halen, M., Helenius, M., Hiekkanen, K., Itälä, T., \& Korhonen, J. (2014). IT Leadership in Finnish Organizations and Digital Transformation. Research Report. Department of Computer Science, Emeritus Mäntylä Martti.

Dias, D. T. M. A. R. (2019). Fatores chaves de sucesso para transformação digital. Dissertação de Mestrado. Fundação Getúlio Vargas, Escola Brasileira de Administração Pública e de Empresas, Centro de Formação Acadêmica e Pesquisa.

Fischer, H.; Mont'alvão, C.; Rodrigues, E. S.; Engelke, A. (2019), Compreensibilidade em textos de e-gov: uma análise exploratória da escrita do INSS. In: $9^{\circ}$ Congresso Internacional de Design da Informação, p. 303-313. Disponível em: https://www.proceedings.blucher.com.br/article-details/33627

INAF, B. Indicador de Alfabetismo Funcional. (2018). Disponível em: $<$ https://acaoeducativa.org.br/wp-content/uploads/2018/08/Inaf2018 Relat\%C3\%B3r io-Resultados-Preliminares v08Ago2018.pdf>. Acesso em: 12 ago. 2021.

Govinfo. Public Law 111 - 274 - Plain Writing Act of 2010 (2010). Disponível em:

<https://www.govinfo.gov/app/details/PLAW-111publ274>. Acesso em: 07 ago. 2021.

Henriette, E. Feki, M., Boughzala, I. (2015); The Shape Of Digital Transformation: A Systematic Literature Review; MCIS Proceedings, Paper 10, pp. 1-19.

Kane, C., Palmer, D., Phillips, A. N., Kiron, D., Buckley, N. (2017) Achieving digital maturity. MIT Sloan Management Review, v. 59, n. 1.

Layne, K., Lee, J. (2001). Developing fully functional e-government: A four stage model. Government information quarterly, Elsevier, v. 18, n. 2, p. 122-136.

Laudon, K. C., Laudon, K. P. (2016). Managing information system: Managing the digital firm (14th ed.). England: Pearson. 
McNutt, K. (2014). Public engagement in the Web 2.0 era: Social collaborative technologies in a public sector context. Canadian Public Administration, 57(1), 49-70.

Macalintal, M., Chepkasova, E. (2017). Transformation in the Era of Digitization: A study of organizations implementing digital transformation projects with integrated project management and change management. Dissertação de Mestrado. Umeå School of Business and Economics.

Morakanyane, R., Grase, A. A., O'Reilly, P. (2017). Conceptualizing Digital Transformation in Business Organizations: A Systematic Review of Literature. In: Bled eConference, p. 21.

Oliveira, R.; Cappelli, C.; Oliveira, J., (2021). Diretrizes para o Design de Visualização da Informação: Estendendo a Linguagem Cidadã. In: Workshop de Computação Aplicada em Governo Eletrônico (WCGE), p. 259-266. ISSN 2763-8723. Disponível em: https://sol.sbc.org.br/index.php/wcge/article/view/15994

Park, S., Gil-Garcia, J. R. (2017). Understanding transparency and accountability in open government ecosystems: The case of health data visualizations in a state government. In Proceedings of the 18th Annual International Conference on Digital Government Research. pp. 39-47.

Resnick, M., (2002). Rethinking Learning in the Digital Age.

Ribeiro, A. Visual Law I Contrato. Behance, (2021). Disponível em: https://www.behance.net/gallery/105020447/Visual-Law-Contrato?tracking source= search projects recommended\%7Ccontrato. Acesso em: 30 de agosto de 2021.

Rogers, D. L. (2016). The Digital Transformation Playbook: Rethink your Business for the Digital Age. New York: Columbia University Press.

Sandberg, J., Mathiassen, L, Napier, N. (2014). Digital options theory for IT capability investment. Journal of the Association for Information Systems, v. 15, n. 7, p. 1.

Shumskaya, D., (2019). Linguagem Clara: uma questão de cidadania corporativa para as instituições financeiras? (Doctoral dissertation, Instituto Politécnico de Lisboa, Escola Superior de Comunicação Social).

Song, C., Lee, J. (2016). Citizens' use of social media in government, perceived transparency, and trust in government. Public Performance \& Management Review, $39(2), 430-453$.

Tadeu, H. F. B., Duarte, A. L. C. M., Chede, C. T. (2018). Transformação Digital: perspectiva brasileira e busca da maturidade digital. Revista DOM. Fundação Dom Cabral. Nova Lima, DOM: v.11, n.35 , p. 32-37, maio/ago. 2018. Acesso em: https://acervo.ci.fdc.org.br/AcervoDigital/Artigos\%20FDC/Artigos\%20DOM\%2035/ Transforma\%C3\%A7\%C3\%A3o\%20Digital\%20perspectiva\%20brasileira\%20e\%20 busca\%20da\%20maturidade\%20digital.pdf. 


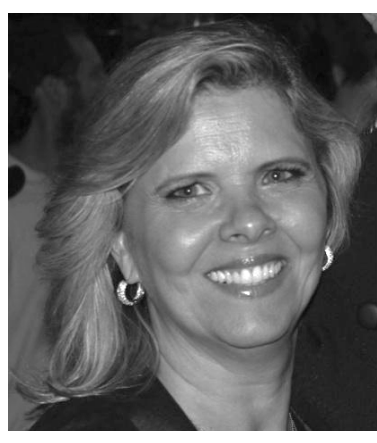

\section{Claudia Cappelli}

Professora do curso de Ciência de Computação da UERJ. Colaboradora do programa de Pós Graduação em Sistemas de Informação da UFRJ. Doutora em Ciências Informática pela PUC-Rio (2009). Mestre em Sistemas de Informação pela Universidade Federal do Rio de Janeiro (2000). Graduada em Informática pela Universidade do Estado do Rio de Janeiro (1985). Realizou estágio Pós-Doutoral junto ao Programa de Pós-Graduação em Informática da Unirio (2010) e na UFRJ (2020). Pesquisadora Jovem Cientista Nosso Estado pela FAPERJ. Fundadora do Instituto Nacional de Ciência e Tecnologia em Democracia Digital (INCT-DD). Pesquisadora em Literacia Digital do IBCIH (Instituto Brasileiro de Cidades Inteligentes e Humanas). Pesquisadora em Linguagem Cidadã no LincLab (Laboratório Interdisciplinar de Linguagem Clara). Membro do Comitê Gestor do programa Meninas Digitais da SBC. Mentora da Fábrica de Startups. Pesquisadora em Inovação no INEI (Instituto Nacional de Empreendedorismo e Inovação). Foi Professora do Departamento de Informática Aplicada da Universidade Federal do Estado do Rio de Janeiro (UNIRIO) (2005 - 2018).

http://lattes.cnpq.br/4930762936357558

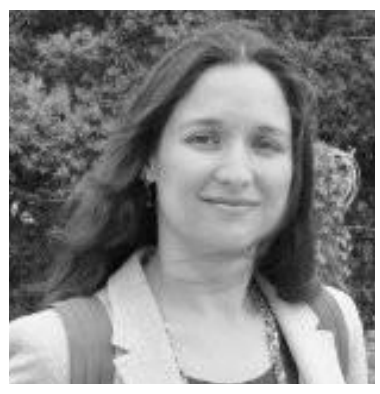

\section{Vanessa Nunes}

Doutora em Engenharia de Sistemas e Computação pela COPPE/UFRJ desde 2014 e mestre em Sistemas de Informação pelo NCE/UFRJ desde 2007, tendo concluído a graduação em Ciência da Computação pela UFRJ em 2004. Pós-doutora pelo Departamento de Ciência da Computação da Universidade de Brasília (UnB) em pesquisas relacionadas aos temas de computação transparente, arquitetura corporativa, modelos de referência para avaliação e evolução de cidades inteligentes e humanas e sistemas multi-agentes. Atua como Professora Substituta no Departamento de Ciência da Computação da Universidade de Brasília. Membro de pesquisa da Rede Brasileira de Cidades Inteligentes e Humanas (RBCIH - www.redebrasileira.org) Participa também na organização da SE7Ti - Tecnologia e Inovação.

http://lattes.cnpq.br/2043415661294559 


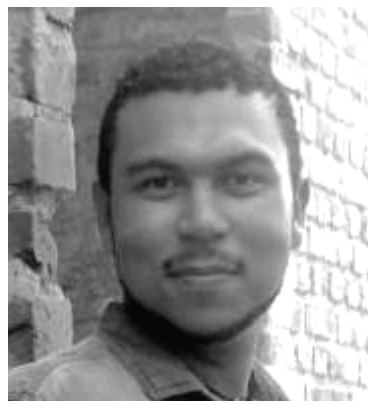

\section{Rodrigo Oliveira}

Mestrando em Informática, linha de pesquisa em Sistemas de Informação pela Universidade Federal do Rio de Janeiro, UFRJ (2019) possui Bacharel em Sistemas de Informação pela Universidade Federal do Estado do Rio de Janeiro, UNIRIO (2018) e Graduado em Design Gráfico pela Universidade do Grande Rio, UNIGRANRIO (2013). Pesquisador em Linguagem Cidadã no LincLab (Laboratório Interdisciplinar de Linguagem Clara). Analista de Geotecnologia na Imagem Geosistemas (img.com.br). Carreira desenvolvida na área de Design e Tecnologia, com experiência em comunicação visual, design de interação e desenvolvimento de software. Com interesses na área de Visualização de Dados, UX Design, Linguagem Simples e Gestão de Processos de Negócios, com ênfase em transparência da informação e automação de soluções em TI.

http://lattes.cnpq.br/1091110605525620 